\title{
Development of Thermoplastic Composites for Visible Parts in Automotive
}

\author{
Thomas Köhler ${ }^{1, a}$, Klaus Vonberg ${ }^{1, b}$, Benjamin Mohr ${ }^{1, c}$, Thomas Gries ${ }^{1, d}$ \\ and Gunnar Seide ${ }^{2, e}$
}

\author{
${ }^{1}$ Institut für Textiltechnik (ITA) der RWTH Aachen University, \\ Otto-Blumenthal-Straße 1, 52074 Aachen, Germany \\ ${ }^{2}$ Department of Biobased Materials / Aachen-Maastricht Institute for Biobased-Materials, \\ Maastricht University, Urmonderbaan 22, 6167 RD Geleen, The Netherlands \\ aThomas.Koehler@ita.rwth-aachen.de, ${ }^{b}$ Klaus.Vonberg@ita.rwth-aachen.de, \\ 'Benjamin.Mohr@ita.rwth-aachen.de, 'Thomas.Gries@ita.rwth-aachen.de, \\ eGunnar.Seide@maastrichtuniversity.nl
}

Keywords: hybrid yarns, fiber reinforced thermoplastic composites, heat pressing, cycle time

\begin{abstract}
In order to reduce $\mathrm{CO}_{2}$ emissions, for the automotive industry, the most promising area of research is lightweight construction. Next to weight reduction, lightweight materials like fiber reinforced thermoplastic composites (FRTC) may also improve mechanical properties of vehicle body parts. FRTCs, so-called organic sheets, have the potential for large scale series production and they can be back moulded due to the thermoplastic matrix. On the other hand high production cycle times and a poor surface quality are limiting their potential. Therefore, ITA's current research approaches these problems in two ways. Nanomodified materials and a new tool concept for heat pressing are going hand in hand and may lead to the technology's breakthrough.

To reduce the cycle times of the production of FRTCs innovative and modified matrix systems are investigated. The goal of the public founded project "VarioOrgano" is to analyze the potential of these modified yarns and the tool system during the FRTC production. Moreover, the capability of these composites in visible parts in automotive applications is investigated. Therefore, the whole process chain from compounding, to melt spinning, commingling and consolidation with a heat press is investigated.

This paper shows the production steps along the process chain to produce these FRTCs with focus on hybrid yarn development and production.
\end{abstract}

\section{Introduction}

A fiber based composite is a material made from reinforcement fibers embedded in a plastic matrix. Composites have a high tenacity in the direction of reinforcement fibers while maintaining a low density. Thus they provide the possibility of weight reduction enabling lightweight applications [1]. For the production of thermoplastic composites, a reinforcement fiber structure is embedded in a thermoplastic matrix. To this end, the matrix is melted during the consolidation process and the reinforcement fibers are being wetted out by matrix material under the influence of pressure. After wetting out the reinforcement fibers the molten matrix is cooled down again. The high viscosity of the thermoplastic melt presents a challenge in the consolidation process. If the pressure is increased too much during consolidation, the reinforcement fibers will become misaligned. If the consolidation time is too extended, the manufacturing process becomes uneconomical. The polymer can be modified by adding nano particles to enhance the mechanical and thermal properties of the matrix systems [2]. By using hybrid yarns the reinforcement and polymer fibers have already been mixed at filament level. Thereby short flow paths are achieved which result in a good wetting out of the reinforcement fibers while achieving short cycle times [3]. Moreover, the combination of good thermal properties in the matrix and short flow paths has the capability to develop composites for surface applications in the automotive industry. The aim of the public funded project "VarioOrgano" is to investigate this topic. 
Depending on the initial fibers different mixing processes are possible like direct spinning, spread mixing and air commingling. The air commingling process is suitable for high flexibility in the initial as well as hybrid yarn design. Air commingling is used to manufacture hybrid yarns by mixing the reinforcement and polymer fibers at filament level with compressed air, ending up with one single-end hybrid yarn of technically endless filaments. A characteristic of air commingled hybrid yarns are slight ondulations in the reinforcement filaments along the roving axis. The ondulations originate from the overfeed during the air commingling process, which is necessary to open up and mix reinforcement and thermoplastic filaments [3, 4].

The scope of this paper is to develop hybrid yarns based on glass fibers and modified nylon 6 fibers that fit the requirements related to processing to fabrics, short flow paths for cycle time reduction during heat pressing and fiber strength. In a first step a parameter set will be defined for the air commingling process. In doing so, the process speed, the pressure inside the air commingling nozzle as well as the overfeed of both fibers during the mixing process will be varied. The different hybrid yarns are later tested for their mechanical strength, their mixing quality and their processability to fabrics [5]. An evaluation of these data is performed to define the best parameter set for the production of a high amount of hybrid yarns.

\section{Consolidation of thermoplastic based composites}

For the production of thermoplastic composites, a textile structure of reinforcement fibers is embedded into a thermoplastic matrix. Embedment is achieved by wetting out the reinforcement fibers with molten thermoplastic material and cooling down the composite afterwards. For this purpose, the thermoplastic material can be present as a film that is stacked on the reinforcement structure before heating up. Another known method is to coat the reinforcement fiber structure with thermoplastic powder [6]. Both methods require the thermoplastic melt to flow half the diameter of a reinforcement roving in order to entirely wet out all filaments. The necessary process time $\mathrm{T}$ to consolidate a thermoplastic composite correlates to the average flow path $\mathrm{x}$ and the consolidation pressure $\mathrm{p}$ as shown in Eq. 1 [7].

$$
\mathrm{T} \sim \frac{\mathrm{x}^{2}}{\mathrm{p}}
$$

The process time can be shortened by increasing the pressure during consolidation. Depending on the consolidation method, this option is limited. In a vacuum bag consolidation process the pressure is limited by ambient pressure. In a consolidation press process, rising the pressure too much might lead to fiber misalignment [8]. Even small shifts of the reinforcement fiber impair the mechanical properties significantly [9]. In an autoclave process, high pressure can be applied without fiber misalignment. However, autoclave equipment is very expensive and the set-up time as well as the batch wise processing limit the application possibilities.

In contrast to pressure, a reduction of the average flow path $\mathrm{x}$ decreases the process time $\mathrm{T}$ by the power of two. The average flow path $\mathrm{x}$ of the thermoplastic melt can be decreased by mixing reinforcement and polymer fibers on filament level. The resulting yarns are called hybrid yarns and have a typical linear density between 500 and 2000 tex for technical applications [3]. An overview of different hybrid yarn types is given in Fig. 1. 


\begin{tabular}{|c|c|c|c|}
\hline $\begin{array}{l}\text { Yarn cross section / } \\
\text { schematic illustration }\end{array}$ & Yarn type & $\begin{array}{l}\text { Arrangement/ } \\
\text { blending of } \\
\text { fibers } \\
\end{array}$ & $\begin{array}{l}\text { Flow path } \\
\text { length }\end{array}$ \\
\hline & $\begin{array}{c}\text { Core-sheath yarn } \\
\text { (sheath from filament } \\
\text { yarn) }\end{array}$ & $\begin{array}{l}\text { Core-sheath } \\
\text { structure/ } \\
\text { low }\end{array}$ & High \\
\hline & Multifilament yarn & $\begin{array}{l}\text { Side by side/ } \\
\text { low }\end{array}$ & High \\
\hline & Multifilament yarn & Random/high & Low \\
\hline & Spun yarn & Random/high & Low \\
\hline & Wrapped yarn & $\begin{array}{l}\text { core/ } \\
\text { low }\end{array}$ & High \\
\hline & $\begin{array}{l}\text { Core-sheath yarn } \\
\text { (sheath from staple } \\
\text { fibers) }\end{array}$ & $\begin{array}{l}\text { Core-sheath } \\
\text { structure/ } \\
\text { low }\end{array}$ & High \\
\hline
\end{tabular}

Fig. 1. Overview of different hybrid yarn types $[10,11]$

\section{Testing methods for hybrid yarns}

The hybrid yarns are analyzed for their strength and mixing as well as processing properties. These testing methods will be explained in the following paragraph.

The fiber damage of the produced hybrid yarns is tested with a tensile test performed by a machine of the type STATIMAT 4U from Textechno Herbert Stein GmbH \& Co. KG, Mönchengladbach, Germany. The tests are executed according to the ITA standard. The specimens are fixed at a length of $135 \mathrm{~mm}$ and the testing speed is $10 \mathrm{~mm} / \mathrm{min}$. In addition to that, the yarns are pre-stressed with $0.5 \mathrm{cN} /$ tex to align the filaments in pulling direction. The experimental setup of the tensile test is shown in Fig. 2 [12].

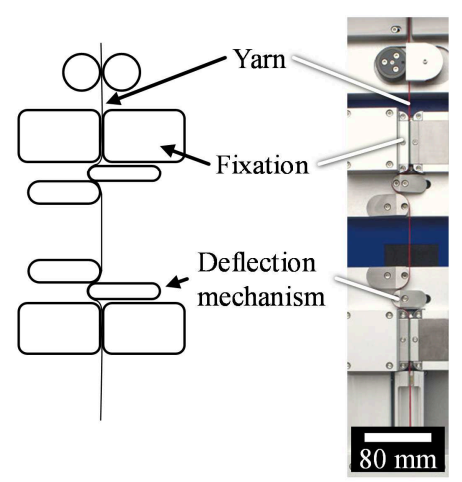

Fig. 2. Tensile test of hybrid yarns with the STATIMAT 4U [12]

The use of a deflection mechanism shall prevent the yarn from breaking at the fixation. Statistical reliability is obtained by sample sizes of 10 . Moreover, influencing factors like ondulation, fiber length and force transmission have to be considered [12].

Beyond the fiber damage, the blending performance of the commingling process has to be determined. In this context, light microscopic pictures are taken and analyzed. Samples of chosen hybrid yarns are fixed in a heat shrink tube and covered with epoxy resin. The obtained cylindrical samples are wet-grinded and polished. In doing so, the surface becomes even, which is essential for images without defects. The schematic illustration of a sample as well as a light microscopic image of a commingled hybrid yarn is shown in Fig. $3[4,12]$. 

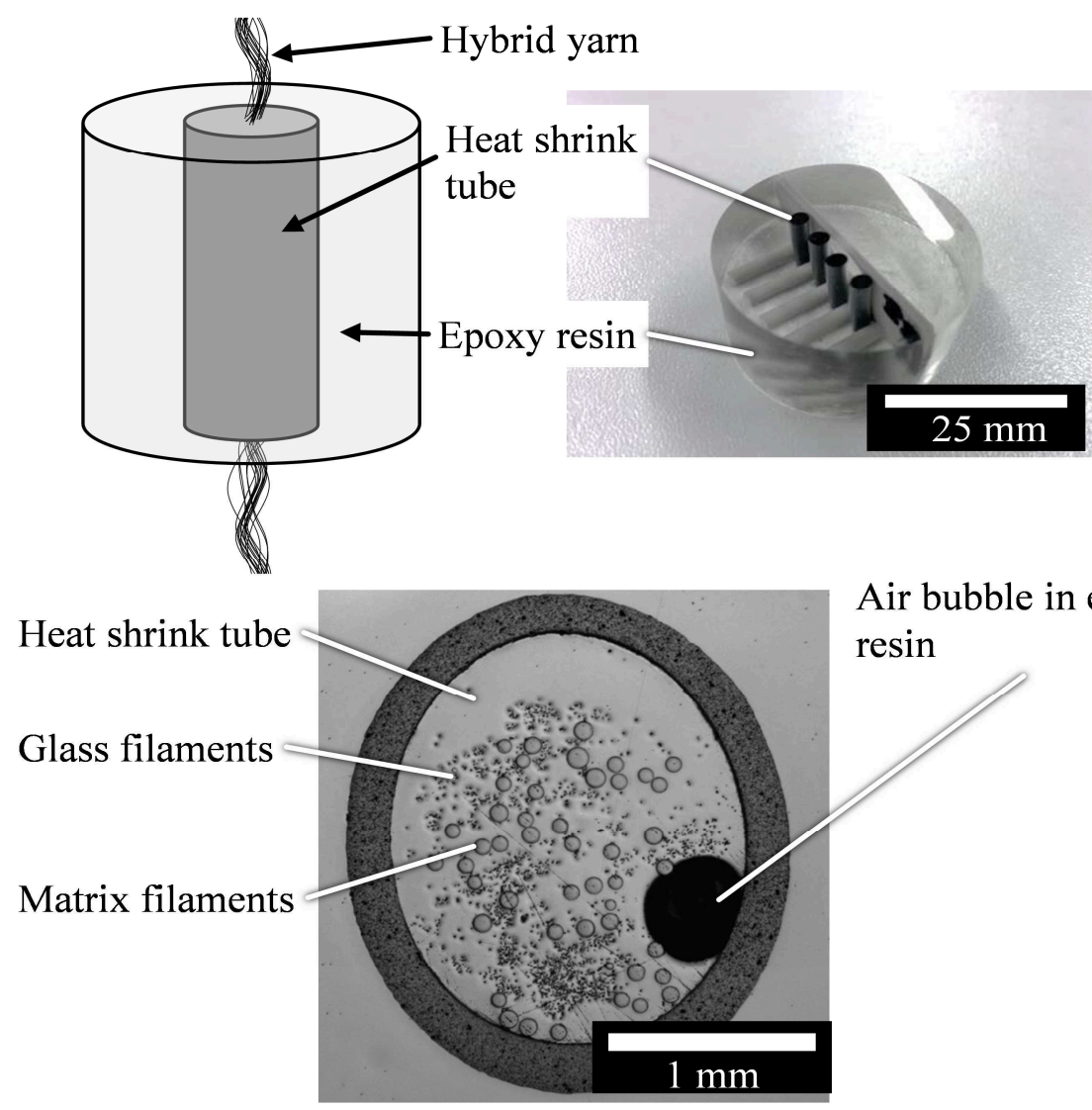

Fig. 3. Schematic illustration of the samples used for examination and light microscopic image of commingled glass and matrix fibers [12]

\section{Applied materials}

In order to manufacture the thermoplastic nanocomposite yarn Polyamide 6 (Ultramid ${ }^{\circledR}$ B24 N 03 from BASF SE, Ludwigshafen, Germany ) and 3M $\mathrm{M}^{\mathrm{TM}}$ Boron Nitride Powder Grade S1-SF from ESK Ceramics GmbH \& Co. KG, Kempten, Germany are used. To get best properties regarding shrinkage of thermoplastic fibers during heat pressing, a Low Oriented Yarn (LOY) meltspinning process is performed (ITA high temperature bicomponent spinning machine by Fourné Polymertechnik, Alfter, Germany). Therefore filaments were spun with a take-up velocity of $800 \mathrm{~m} / \mathrm{min}$ without additional drawing. Yarns with up to $10 \mathrm{wt} \%$ of Boron nitride particles were successfully spun without out fiber brakes in time intervals of 30 minutes. After 30 minutes the process had to be interrupted due to the change of the bobbin.

For further production to hybrid yarns commercial available glass fibers with 600 tex type TUFROV 4510 from PPG Industries Glass \& Fiber Glass GmbH, Düren are purchased. Moreover, the fiber is provided with a sizing to improve bonding with the PA matrix.

\section{Development of hybrid yarns based on glass and nylon 6 fibers}

The hybrid yarns are produced by an air jet commingling process. They consist of glass fibers (GF) and nylon 6 fibers (PA). The test set up is shown in Fig. 4. The air commingling method combines reinforcement filaments with matrix filaments by feeding both components into a commingling nozzle. The commingling nozzle has one or more additional openings transvers to the yarn path, through which compressed air passes into the yarn path. The compressed air creates turbulences that mix the filaments of both components. The intensity of the turbulent flow is increased or decreased by changing the air pressure. Increasing the air pressure also results in more filament breaks and increases the production cost. Another important parameter is the overfeed, generated by the relative speed between the stabilizing godet and the feeding godets. Overfeeding allows sufficient 
movement of the filaments for the mixing in the commingling nozzle. Furthermore, the production speed is a process parameter $[3,4]$.

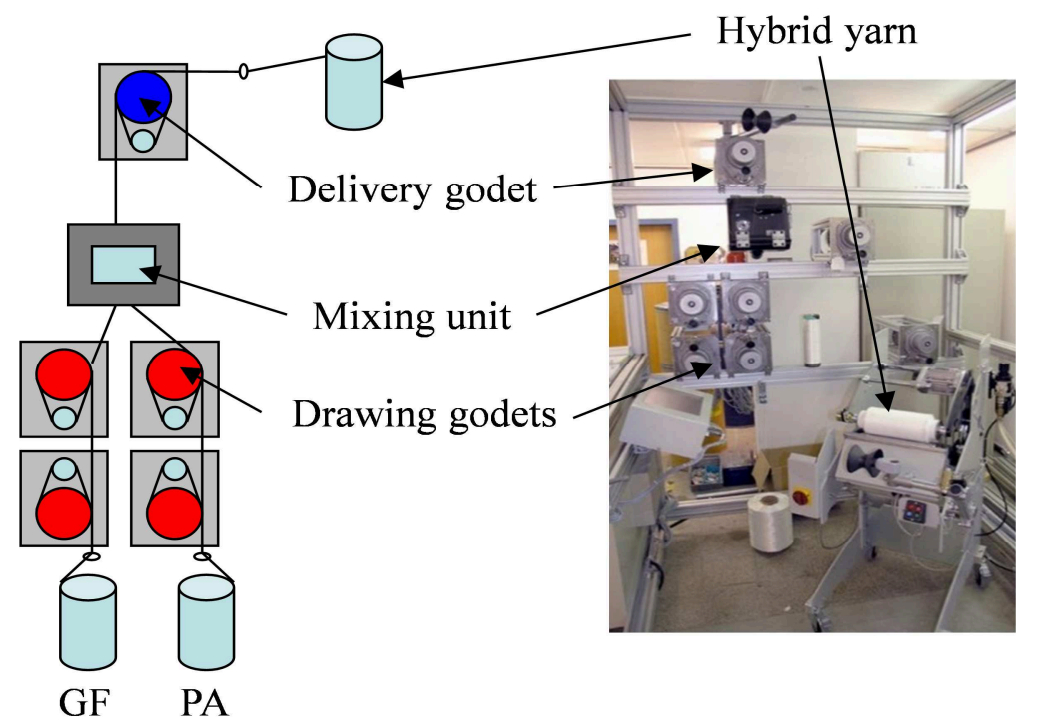

Fig. 4. Set up for air jet commingling

During the tests different nozzles for air jet mixing with defined overfeed are evaluated. These nozzles are

- Test A: P24 nozzle with overfeed GF $1 \%$ and PA $3 \%$,

- Test B: $\quad$ P24 nozzle with overfeed GF $1 \%$ and PAF $4 \%$,

- Test C: BCFW nozzle with overfeed GF $1 \%$ and PAF $3 \%$ and

- Test D: $\quad$ BCFW nozzle with overfeed GF $1 \%$ and PAF $4 \%$.

The parameter set is shown in Table 1. The speed is varied between 60 and $90 \mathrm{~m} / \mathrm{min}$ and the pressure between 3 and 5 bar. The overfeed is defined in pretests and will not be changed during the following hybrid yarn development.

Table 1. Parameter set for the commingling trials A, B, C and D

\begin{tabular}{|ll|l|l|l|l|l|}
\hline speed [m/min] & pressure [bar] & 3 & 3,5 & 4 & 4,5 & 5 \\
\hline 60 & 01 & 02 & 03 & 04 & 05 \\
\hline 75 & 06 & 07 & 08 & 09 & 10 \\
\hline 90 & 11 & 12 & 13 & 14 & 15 \\
\hline
\end{tabular}

First, hybrid yarns are developed based on the given parameter sets. Then several hybrid yarns are selected for further testing and analysis.

\section{Analysis and Testing}

The hybrid yarns A02, A05, A09, B02, B05, B10, C02, C05, C10, D02, D05 and D10 as the most promising samples are selected for further testing. All samples are characterized in terms of their tensile strength, their processability and their mixing behavior.

Fiber damage caused by the commingling process is determined by comparing the tensile strength of the hybrid yarns to an initial glass fiber roving. The results are shown in Fig. 5. The sample GF 1 is the tensile strength of the initial glass fiber roving. C05 is the finally selected sample with best material properties based on tensile strength, mixing behavior and processability. 


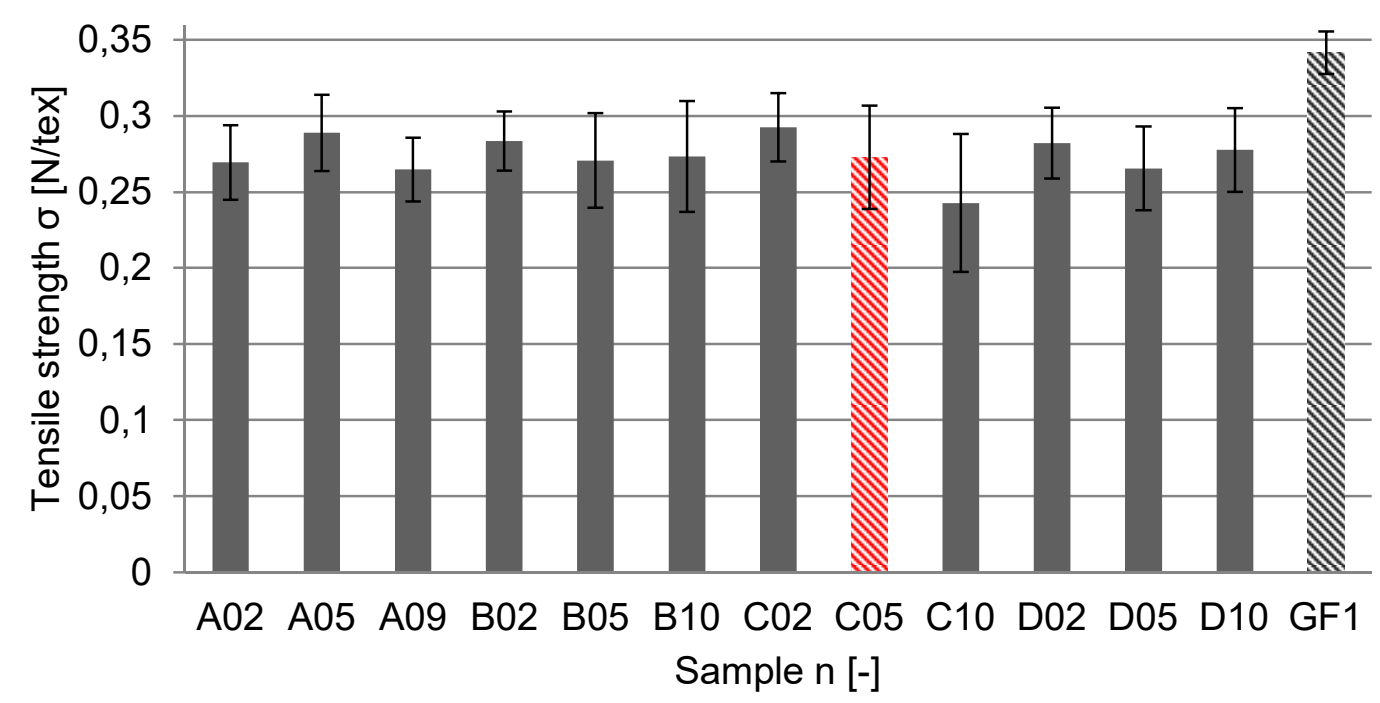

Fig. 5. Tensile strength of hybrid yarns of chosen parameter sets

The mixing behavior was determined using microscopy analysis as described above. The microscopy pictures were assessed qualitatively according to the parameters opening and mixing as shown in Table 2.

Table 2. Mixing behavior assessed qualitatively. $+=$ good, o $=$ neutral, $-=$ poor

\begin{tabular}{|l|l|l|l|l|l|l|l|l|l|l|l|l|}
\hline sample: & A02 & A05 & A09 & B02 & B05 & B10 & C02 & C05 & C10 & D02 & D05 & D10 \\
\hline opening & + & $\circ$ & - & - & $\circ$ & - & $\circ$ & + & $\circ$ & + & + & + \\
\hline mixing & - & - & $\circ$ & - & - & $\circ$ & $\circ$ & + & $\circ$ & + & $\circ$ & + \\
\hline
\end{tabular}

It can be seen, that only three samples, C05, D02 and D10 are assessed positive regarding both, opening and mixing. All these samples are produced with an overfeeding of $1 \%$ GF and $4 \%$ PA. The higher overfeeding of the PA fibers enables better opening and mixing behavior on the one hand. One the other hand the processablity to textiles will also be influenced.

For assessing the processability the assumption that loops will cause problems in a following weaving process is made. For each sample the amount of loops within one meter of the hybrid yarn is counted and the sizes of the loops are measured. The procedure is repeated 5 times for each sample. The results are given in Fig. 6. The finally selected sample C05 is marked in red. It can be seen, that $\mathrm{C} 05$ provides the smallest average maximum loop size, which indicates, that this sample might be the most promising sample regarding the further processing to fabrics.

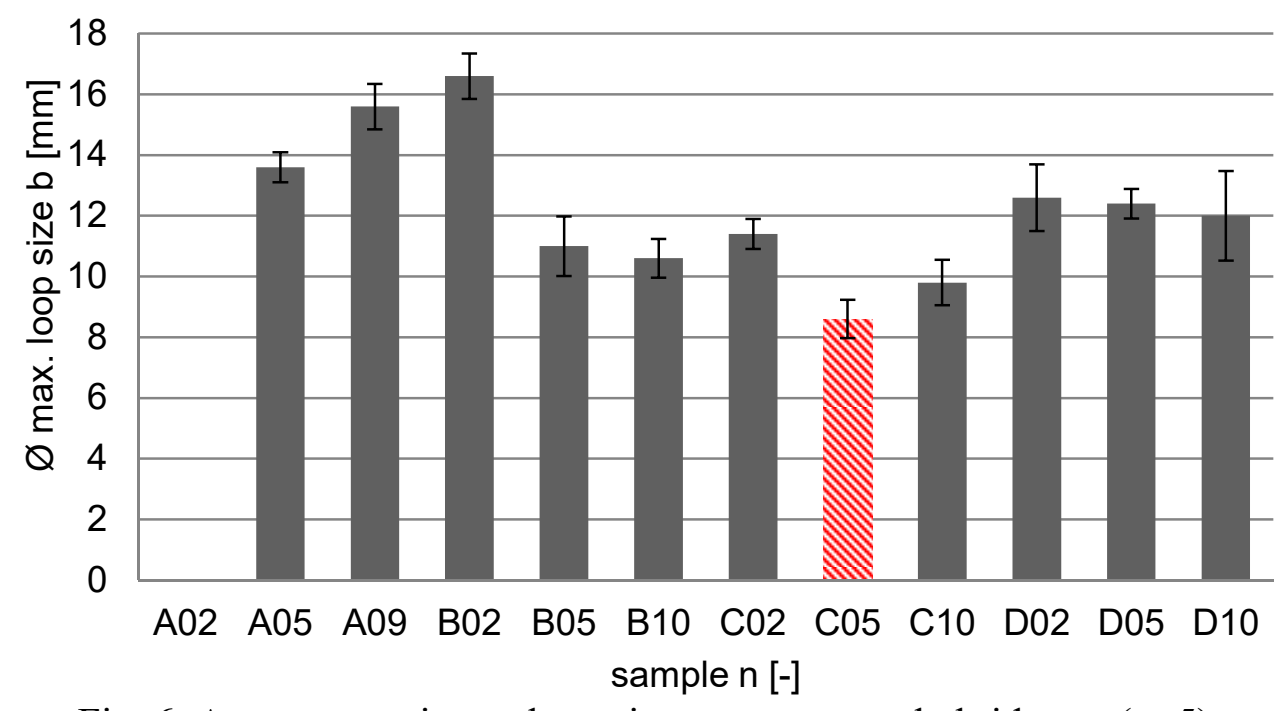

Fig. 6. Average maximum loop size on one meter hybrid yarn $(n=5)$ 


\section{Conclusions}

Regarding the analysis of the hybrid yarn samples in terms of processability, tensile strength and mixing behavior, the results differ from parameter to parameter. In order to find a final parameter set for the following production of textile fabrics and further thermoplastic fiber reinforced composites, all samples were assessed in following scheme:

For each criteria 1 to 6 points are distributed to all samples. Thus in total a maximum of 18 points can be achieved, which means a $100 \%$ fulfillment of the requirements.

In detail this means for the tensile strength, the best sample is rated with six points, while all others are compared to that. In terms of processability the max. loop size is considered to be the most important criteria. The sample with the smallest loop size is rated with six points, while the other samples are compared to that. Regarding the mixing behavior for both parameters, opening and mixing, three points are distributed, which means a sample with equally good mixing and opening results get six points. The results of the Assessment are given in Table 3.

Table 3. Assessment of the analyzing results in order to choose one sample for further processing.

\begin{tabular}{|c|c|c|c|c|c|c|c|c|c|}
\hline \multicolumn{3}{|c|}{$\begin{array}{c}\text { Mechanical } \\
\text { properties }\end{array}$} & \multicolumn{7}{|c|}{$\begin{array}{c}\text { Mixing } \\
\text { behaviour }\end{array}$} \\
\hline $\begin{array}{l}\frac{0}{2} \\
\text { 范 }\end{array}$ & $\begin{array}{l}\text { Tensile } \\
\text { strength }\end{array}$ & $\stackrel{0}{\stackrel{0}{\Xi}}$ & $\begin{array}{c}\max . \varnothing \\
\text { loop size }\end{array}$ & $\stackrel{\mathscr{0}}{\leftrightarrows}$ & 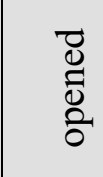 & 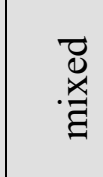 & .厃̊n & 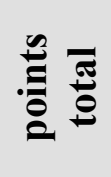 & 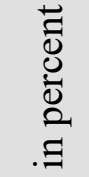 \\
\hline & {$[\mathrm{N}]$} & & {$[\mathrm{mm}]$} & & {$[-]$} & {$[-]$} & & & {$[\%]$} \\
\hline A02 & 269,48 & 2 & 0 & 6 & + & - & 2 & 10 & 56 \\
\hline A05 & 288,95 & 5 & 13,6 & 2 & 0 & - & 3 & 10 & 56 \\
\hline A09 & 264,84 & 2 & 15,6 & 1 & - & $\circ$ & 3 & 6 & 33 \\
\hline B02 & 283,5 & 4 & 16,6 & 1 & - & - & 2 & 7 & 39 \\
\hline B05 & 270,82 & 3 & 11 & 4 & $\circ$ & - & 3 & 10 & 56 \\
\hline B10 & 273,48 & 3 & 10,6 & 5 & - & $\circ$ & 3 & 11 & 61 \\
\hline $\mathrm{C} 02$ & 292,57 & 6 & 11,4 & 4 & $\circ$ & $\circ$ & 4 & 14 & 78 \\
\hline C05 & 272,9 & 3 & 8,6 & 6 & + & + & 6 & 15 & 83 \\
\hline $\mathrm{C} 10$ & 242,79 & 1 & 9,8 & 6 & $\circ$ & $\circ$ & 4 & 11 & 61 \\
\hline D02 & 282,23 & 4 & 12,6 & 3 & + & + & 6 & 13 & 72 \\
\hline D05 & 265,62 & 2 & 12,4 & 3 & + & 0 & 5 & 10 & 56 \\
\hline D10 & 277,78 & 3 & 12 & 3 & + & + & 6 & 12 & 67 \\
\hline
\end{tabular}

Thus sample C05 reaches the highest score. The processing parameters of sample C05 will be chosen for further manufacturing of fabrics and FRTCs in the near future. 


\section{Acknowledgements}

Supported by:

貌 Federal Ministry of Economics
and Technology and Technology

on the basis of a decision on the basis of a decision
by the German Bundestag
This research was funded by the Federal Ministry of Economics and Technology. We thank our corporate partner Sigel GmbH, Kirchheim/Teck-Jesingen, Germany who provided expertise that greatly assisted the research and developed the heating tool.

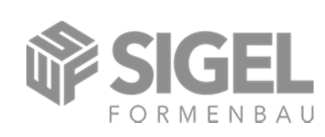

FORMENBAU

\section{References}

[1] F. H. Henninger, Beitrag zur Entwicklung neuartiger Fertigungsverfahren zur Herstellung von bauteilen aus kontinuierlich faserverstärkten Thermoplasten, Dissertation, Kaiserslautern, Tech. Univ., 2005

[2] R. Brüll, A. Hütten, G. Seide, T. Gries, Using Nanoscale Fillers to improve the thermal properties of fibre reinforced thermoplastic composites regarding processing times, CAMX 2015, Dallas, Texas, October $26^{\text {th }}-29^{\text {th }} 2015$.

[3] B. Choi, Entwicklung von Commingling-Hybridgarnen für langfaserverstärkte thermoplastische Verbundwerkstoffe, Dissertation, Dresden, TUDpress, 2005.

[4] P. Kravaev, Prozesskette für die Herstellung nanomodifizierter thermoplastischer Verbundbauteile, Dissertation, Shaker Verlag, Aachen, Techn. Univ., 2012.

[5] R. Alagirusamy, R. Fangueiro, V. Ogale, N. Padaki, Hybrid, Yarns and Textile Preforming for Thermoplastic Composites, Textile Progress 38 (2006) 1-71.

[6] F. H. Curzio, Method and apparatus for producing blends of resinous, thermoplastic fiber, and laminated structures produced therefrom, US Patent 4,539,249. Date of patent Sep. 3, 1995.

[7] T. Løgstrup Andersen, A. Lystrup, H. Knudsen, B. Lichscheidt, Glas/PET-fiber hybridgarn til fremstilling af fiberkompositter, Edition 1, Volume 1, Risø: Forskningscenter Risø, A/S Kaj Neckelmann, 1994.

[8] J. Jakobsen, K. V. Jacobsen, M. M. Jensen, J. Ø. Kristensen, Fremstilling af termoplastiske fiberkompositter ved presning,Aalborg, Institut for Mekanik og Produktion Maskin og Produktion, Sep. 19, 2014.

[9] T. Raghavalu. P. Durai, H. Lilholt, F. Aviles, T. Løgstrup Andersen, H. Knudsen, Fibre waviness and misalignment measurement of unidirectional glass/LPET commingled composites Effect on mechanical properties, Risø, 2013, Risoe International Symposium on Materials Science, Proceedings, P. 357.

[10] R. Alagirusamy, V. Ogale, Commingled and Air Jet-textured Hybrid Yarns for Thermoplastic Composites, Journal of Industrial Textiles 33 (2004) 223-243.

[11] C. Cherif, Textile Werkstoffe für den Leichtbau, Berlin, Heidelberg, DE: Springer, 2011.

[12] Rebmann, P.; Brüll, R.; Vonberg, K.; Seide, G.; Gries, T., Manufacturing of thermoplastic, unidirectional composites from nanomodified PP/GF hybrid yarns by microwave compression molding, CAMX The Composites and Advanced Materials Expo, September 26-29, 2016, Anaheim, California. - Arlington, VA : ACMA ; Diamond Bar, CA : SAMPE, 2016

[13] TUFRov 4510. 2017. PPG Industries, Inc., Pittsburgh, PA. 29.01.2017 $<$ http://www.ppgfiberglass.com/getmedia/db1c14d6-4b68-4a1a-82e1-

f261d287fbf9/TUFROV_4510.pdf.aspx>. 